\title{
STRUKTUR PENDAPATAN, TINGKAT KESEJAHTERAAN DAN FAKTOR \\ PRODUKSI AGROFORESTRI KOPI PADA KESATUAN PENGELOLAAN \\ HUTAN LINDUNG BATUTEGI \\ (Studi di Gabungan Kelompok Tani Karya Tani Mandiri)
}

\section{STRUCTURE OF INCOME, WELFARE LEVEL AND PRODUCTION FACTORS COFFEE AGROFORESTRY AT PROTECTION FOREST MANAGEMENT UNIT OF BATUTEGI (Study In Karya Tani Mandiri Group)}

\author{
Sri Winarni, Slamet Budi Yuwono, dan Susni Herwanti \\ Jurusan Kehutanan Fakultas Pertanian Universitas Lampung \\ Jl. Prof. Dr. Soemantri Brojonegoro no. 1 Bandar Lampung \\ E-mail: wiwin2590@yahoo.co.id \\ No. Telpon: 08990528092
}

\begin{abstract}
ABSTRAK
Program Hutan Kemasyarakatan ( $\mathrm{HKm})$ merupakan salah satu upaya untuk menyelamatkan hutan sekaligus memberikan manfaat pada masyarakat. Masyarakat diberikan izin untuk mengelola hutan dengan syarat tidak mengembangkan jenis tanaman dengan sistem monokultur melainkan dengan sistem kebun campuran atau agroforestri. Strata tajuk lengkap yang terbentuk dari sistem agroforestri memberikan manfaat ekonomis dan ekologis yang penting bagi petani, salah satunya dapat memberikan pendapatan bagi petani dan mencegah terjadinya banjir. Sehingga penerapan sistem agroforestri pada lahan HKm diharapkan menjadi solusi untuk kebutuhan lahan sebagai faktor produksi sekaligus untuk pemulihan hutan terutama fungsi life support system. Tujuan penelitian untuk mengetahui struktur pendapatan dan faktor yang mempengaruhi pendapatan serta tingkat kesejahteraan petani agroforestri kopi sebagai peserta HKm. Untuk menganalisis faktor-faktor yang mempengaruhi pendapatan petani menggunakan regresi linear berganda dan untuk mengetahui tingkat kesejahteraan petani menggunakan pendapatan yang disetarakan dengan harga beras menurut Sajogyo 1997. Dari hasil perhitungan, diketahui pendapatan petani dari agroforestri kopi sebesar Rp 14.649.631/KK/Tahun dan Rp 6.321.690/KK/Tahun dari kegiatan non agroforestri yang didominasi berladang. Sebanyak $38,10 \%$ petani sejahtera berdasarkan pendapatan agroforestri kopi di lahan HKm. Hasil analisis, luas lahan garapan dan jumlah jenis tanaman berpengaruh nyata terhadap peningkatan pendapatan petani.
\end{abstract}

Kata kunci : pendapatan, faktor pendapatan, tingkat kesejahteraan

\section{ABSTRACT}

Community forestry program is an effort to save the forests while providing benefits to society. Society was given license to manage forests laden not develop plant species monoculture systems but with agroforestry systems. Canopy multi strata agroforestry systems of benefits economical and ecological that matter to farmers, one of which can provide income for farmers. So that the implementation of agroforestry systems community forestry land is expected to be a solution the needs of land as a factor of production as well as to the recovery of the forest is mainly a function of the life support system. The goal of the research determined the structure of income, the factors that influence of income and welfare level of coffee agroforestry as participants community forestry program. To analyze factors affecting farmers' income analyzed by linear regression of multiple and welfare of farmers based price 
of rice by Sajogyo 1997. From the reckoning, income of farmers amounted of coffee agroforestry to $R p$ 14.649.631/KK/Year and $R p$ 6.321.690/KK/year of activity non agroforestry dominated farming and as much as 38,10\% of farmers prosperous based on income from the activity coffee agroforestry at community forestry. The results regression analysis variables influential real against earnings agroforestry is the land area and the dependents of family.

Key words: income, income factors, welfare level

\section{PENDAHULUAN}

Hutan Kemasyarakatan $(\mathrm{HKm})$ merupakan hutan negara yang pemanfaatan utamanya ditujukan untuk memberdayakan masyarakat setempat yang memiliki ketergantungan terhadap sumber daya hutan dalam memenuhi kebutuhan hidup dengan syarat tidak merubah fungsi pokok hutan. Salah satu hutan negara yang ditetapkan sebagai areal kerja HKm yaitu hutan lindung (Peraturan Menteri Nomor P.88/Menhut-II/2014). Hutan lindung adalah kawasan hutan yang mempunyai fungsi pokok sebagai perlindungan sistem penyangga kehidupan untuk mengatur tata air, mencegah banjir, mengendalikan erosi, mencegah intrusi air laut dan memelihara kesuburan tanah (UU RI No 41 tahun 1999). Program HKm pada hutan lindung tidak memperkenankan masyarakat untuk mengembangkan tanaman dengan sistem monokultur seperti pada areal-areal perkebunan (nanas, tebu, karet, nilam dan sawit) tetapi ditekankan untuk mengembangkan jenis tanaman dengan strata tajuk lengkap seperti pada sistem kebun campuran atau agroforestri (Wulandari, 2009).

Srata tajuk yang terbentuk dari sistem agroforestri memberikan keuntungan baik secara ekologi maupun ekonomi. Menurut Wulandari (2009), secara ekologi dapat mengurangi terjadinya kebanjiran karena hujan akan jatuh pada tajuk tinggi, kemudian ke tajuk sedang dan terakhir ke tajuk rendah pada akhirnya air yang jatuh pada permukaan tanah hanya berupa tetesan saja. Sementara secara ekonomi dapat memberikan peningkatan pendapatan karena sistem agroforestri membantu masyarakat untuk tetap mendapatkan hasil yang maksimal pada pengusahaan lahan yang sempit. Berdasarkan hal tersebut, maka diharapkan program HKm dengan sistem kebun campuran atau agroforestri dapat menjadi solusi untuk kebutuhan lahan sebagai faktor produksi sekaligus untuk pemulihan hutan terutama fungsi life support system.

Semenjak tahun 2007 hingga saat ini Kesatuan Pengelolaan Hutan Lindung (KPHL) Batutegi menerapkan program HKm dan masyarakat pengelola sudah sejak dulu menerapkan pola tanam agroforestri kopi. Namun sejauh ini belum diketahui apakah kultur teknis agroforestri kopi mampu dalam pemulihan fungsi hutan lindung sekaligus berkontribusi nyata dalam pendapatan dan peningkatkan kesejahteraan petani anggota gabungan kelompok tani (Gapoktan) Karya Tani Mandiri sebagai peserta HKm. Penelitian ini dilakukan untuk mengetahui struktur pendapatan, tingkat kesejahteraan dan faktor yang mempengaruhi pendapatan petani agroforestri kopi.

\section{METODE PENELITIAN}

Penelitian dilaksanakan di KPHL Batutegi pada Maret - Juli 2015. Objek penelitian adalah anggota kelompok tani pada Gapoktan Karya Tani Mandiri. Alat yang digunakan dalam penelitian terdiri dari alat tulis, kamera, komputer dan kalkulator. Bahan yang digunakan yaitu kuesioner. Data primer yang dikumpulkan yaitu identitas responden (nama, alamat, umur, jenis kelamin, jumlah anggota keluarga, tingkat pendidikan dan etnis), jenis tanaman yang diusahakan pada pola tanam agroforestri kopi dan kegiatan non agroforestri responden. Data tersebut diperoleh melalui metode wawancara. Data sekunder berupa data 
statistik jumlah penduduk dan kondisi lokasi penelitian yang diperoleh melalui studi pustaka dari Dinas Kehutanan Provinsi Lampung dan kantor KPHL Batutegi.

Pengambilan sampel responden dilakukan secara purposive sampling. Sampel responden dipilih Gapoktan Karya Tani Mandiri dengan jumlah anggota 656 KK dengan luas lahan 1.977,60 ha, hal ini dikarenakan pada Gapoktan Karya Tani Mandiri memiliki jumlah anggota dan luas lahan garapan HKm paling banyak dibandingkan dengan Gapoktan yang lain, sehingga dianggap mewakili. Pendapatan rumah tangga petani mengacu pada Koswara 2006 dalam Lestari (2011) sebagai berikut:

Pendapatan dari Agroforestri kopi pada lahan HKm

$I_{H K m}=\Sigma R_{H K m}-\Sigma C_{H K m}$

Keterangan:

$\mathrm{I}_{\mathrm{HKm}} \quad=$ pendapatan $(\mathrm{Rp} /$ Tahun $)$

$\mathrm{R}_{\mathrm{HKm}} \quad=$ penerimaan dari agroforestri kopi di lahan $\mathrm{HKm}(\mathrm{Rp} / \mathrm{Tahun})$

$\mathrm{C}_{\mathrm{HKm}} \quad=$ pengeluaran untuk pengelolaan agroforestri kopi di lahan $\mathrm{HKm}(\mathrm{Rp} / \mathrm{Tahun})$

Pendapatan dari non agroforestri

$I_{n H K m}=\Sigma R_{n H K m}-\Sigma C_{n H K m}$

Keterangan:

$I_{n H K m}=$ pendapatan total dari kegiatan non agroforestri $(\mathrm{Rp} / \mathrm{Tahun})$

$R_{n H \mathrm{Km}} \quad=$ penerimaan masing-masing dari kegiatan non agroforestri (Rp/Tahun)

$C_{n H K m}=$ pengeluaran untuk kegiatan non agroforestri $(\mathrm{Rp} / \mathrm{Tahun})$

Analisis faktor-faktor yang mempengaruhi pendapatan responden dengan variabel luas lahan, jumlah jenis tanaman (Zega, 2013) dan jumlah tanggungan keluarga (Patty, 2010), berdasarkan regresi linier berganda dengan modifikasi rumus sebagai berikut:

$\left[\mathrm{Y}_{\mathrm{i}}\right]=\mathrm{a}+\left[\mathrm{bx}_{1}\right]_{\mathrm{i}}+\left[\mathrm{bx}_{2}\right]_{\mathrm{i}}+\left[\mathrm{bx}_{3}\right]_{\mathrm{i}}+\mathrm{e}_{\mathrm{i}}$

Keterangan:

$\mathrm{Y}=$ Pendapatan responden dari kegiatan $\mathrm{HKm}$ (Jt/Tahun)

a $\quad=$ Konstanta

$\mathrm{b}=$ Angka arah atau koefisien regresi

e $\quad=$ Standar eror

$\mathrm{X}_{1} \quad=$ Luas (ha)

$\mathrm{X}_{2} \quad=$ Jumlah jenis tanaman (Jenis/ha)

$\mathrm{X}_{3} \quad$ = Jumlah tanggungan keluarga (Jiwa/KK)

Kesejahteraan rumah tangga responden dianalisis menggunakan persamaan menurut Sajogyo 1997 dalam Ayu (2014) sebagai berikut:

1. Paling miskin, apabila pengeluaran per kapita < dari $180 \mathrm{~kg}$ setara nilai beras/tahun.

2. Miskin sekali, apabila pengeluaran per kapita 181-240 kg setara nilai beras/tahun.

3. Miskin, apabila pengeluaran per kapita $241-320 \mathrm{~kg}$ setara nilai beras/tahun.

4. Nyaris miskin, apabila pengeluaran per kapita 321-480 kg setara nilai beras/tahun.

5. Cukup, apabila pengeluaran per kapita $481-960 \mathrm{~kg}$ setara nilai beras/tahun.

6. Hidup layak, apabila pengeluaran per kapita > dari $960 \mathrm{~kg}$ setara nilai beras/tahun.

\section{HASIL DAN PEMBAHASAN}

\section{A. Karakteristik Responden}

Umur sebagian besar responden berkisar 18-65 tahun $(97,62 \%)$ berdasarkan WHO tahun 2015 tergolong dalam kategori umur pemuda. Menurut Hakam (2012) pemuda merupakan bagian dari masyarakat yang produktif. Pohan (2008) mengatakan petani umur 
produktif masih potensial untuk mengelola usahataninya. Sebesar 59,52\% responden mengeyam pendidikan sekolah dasar. Menurut Cahyono (2011) tingkat pendidikan akan mempengaruhi pola pikir dan prilaku petani terhadap hutan (Gambar 1).

a)

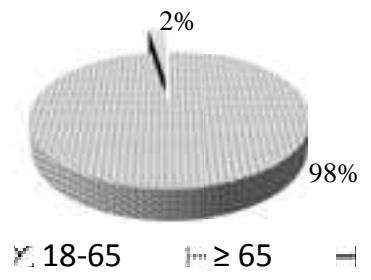

b)

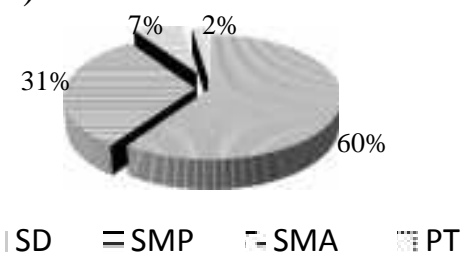

Gambar 1. Distribusi responden menurut umur (a) dan tingkat pendidikan (b).

Jumlah tanggungan keluarga responden berkisar 3-5 Jiwa/KK (52,38\%). Sebanyak $57,14 \%$ responden mengusahakan kegiatan non agroforestri dalam mencukupi kebutuhan hidup sehari-hari. Jenis kegiatan non agroforestri yang dilakukan responden antara lain yaitu: peyedia jasa ojek, berladang, berdagang, buruh tani, bertani sawah dan berternak. Sebanyak $71,43 \%$ responden berasal dari etnis jawa, disusul sunda dan semendo (Gambar 2).

a)

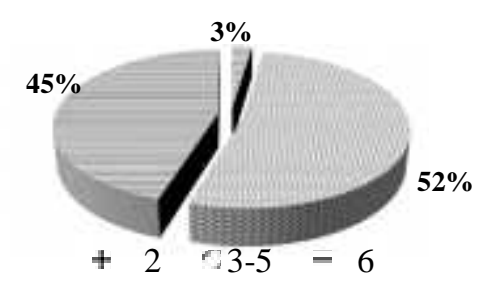

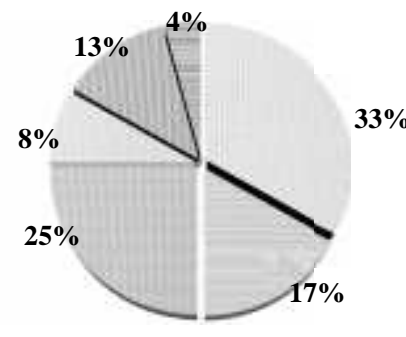

c) b)

: Berladang
Berternak
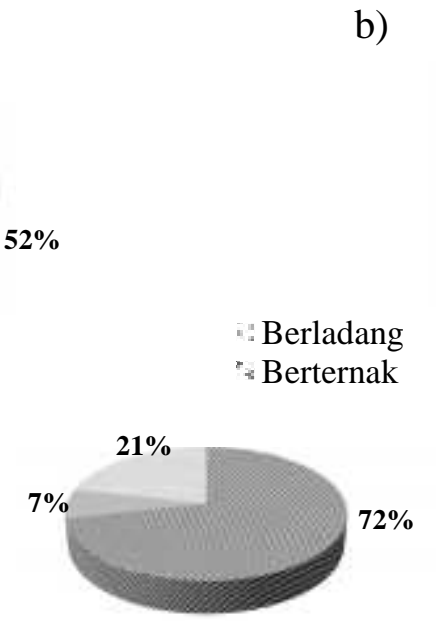

Sawa $s$ Semendo $s$ Sunda

Gambar 2. Distribusi responden berdasarkan jumlah tanggungan keluarga (a) kegiatan non agroforestri (b), dan etnis (c).

Sebagian besar responden dari $42 \mathrm{KK}$, sebanyak $21 \mathrm{KK}$ atau $(76,19 \%)$ memiliki lahan garapan HKm dengan luas 1-2 ha, sedangkan sisanya memiliki luas 1 ha dan 2 ha. Distribusi lahan responden dapat dilihat pada Tabel 1.

Tabel 1. Luas lahan HKm garapan responden.

\begin{tabular}{|c|c|c|}
\hline \multirow[t]{2}{*}{ Luas } & \multicolumn{2}{|c|}{ Jumlah } \\
\hline & KK & $(\%)$ \\
\hline 1 & 6 & 14,29 \\
\hline $1-2$ & 32 & 76,19 \\
\hline 2 & 4 & 9,52 \\
\hline Jumlah & 42 & 100,00 \\
\hline
\end{tabular}


Luas lahan merupakan salah satu faktor produksi yang mempengaruhi besar kecilnya pendapatan karena besar atau kecilnya luasan lahan mempengaruhi jumlah produksi dan pendapatan responden. Phahlevi (2007), mengatakan luas lahan pertanian akan mempengaruhi skala usaha yang pada akhirnya akan mempengaruhi efisien atau tidaknya suatu usaha pertanian, sering kali dijumpai semakin luas lahan yang dipakai dalam usaha pertanian semakin tidak efisien lahan tersebut. Namun, untuk petani penggarap HKm luas atau sempitnya lahan, menurut Ayu (2014) harus mengacu pada Peraturan Menteri No. P.14/Menhut-II/2012 tentang Pedoman Penyelengaraan Rehabilitasi Hutan dan Lahan Tahun 2012, dimana kegiatan rehabilitasi kawasan hutan konservasi/lindung dilakukan dengan pengayaan tanaman kayu minimum 200 batang/ha.

\section{B. Struktur Pendapatan Anggota Kelompok Tani}

\section{a. Pendapatan dari kegiatan agroforestri kopi}

Berdasarkan kegiatan agroforestri kopi di lahan $\mathrm{HKm}$ responden memiliki pendapatan yaitu berkisar Rp 4.000.000/KK/Tahun-Rp 65.000.000/KK/Tahun, dengan pendapatan ratarata $\mathrm{Rp}$ 14.649.631/KK/Tahun. Persentase penyebaran pendapatan responden tersebut dapat dilihat pada Tabel 2.

Tabel 2. Pendapatan responden dari kegiatan agroforestri kopi.

\begin{tabular}{|c|c|c|c|c|}
\hline \multirow[t]{2}{*}{ Kategori } & \multicolumn{2}{|c|}{ Jumlah } & \multirow[t]{2}{*}{ Rp /KK/Tahun } & \multirow[t]{2}{*}{$\overline{\text { Luas (ha) }}$} \\
\hline & KK & $(\%)$ & & \\
\hline Paling rendah & $\overline{5}$ & 11,90 & 9.000 .000 & $0,50-0,75$ \\
\hline Rendah & 21 & 50,00 & $9.100 .000-25.000 .000$ & $1,00-2,00$ \\
\hline Tinggi & 10 & 23,81 & $25.100 .000-34.000 .000$ & $1,00-2,00$ \\
\hline Sangat Tinggi & 6 & 14,28 & 34.000 .000 & $1,50-4,00$ \\
\hline
\end{tabular}

Sumber: Data primer (2015).

Sebanyak 6 KK $(14,28 \%)$ responden berpendapatan dikategorikkan sangat tinggi. Berdasarkan luas pengusahaan lahan, sebagian besar responden yang berpendapatan sangat tinggi mengusahakan lahan seluas 2,5 ha, sementara sebagian besar responden berpendapatan dalam kategori paling rendah mengusahakan lahan $\mathrm{HKm}$ seluas $0,5 \mathrm{ha}$, hal ini sesuai dengan hasil penelitian Patty (2010) yang menyatakan bahwa luas lahan berpengaruh signifikan terhadap pendapatan petani. Data ini menunjukan bahwa semakin luas lahan yang diusahakan responden, maka akan semakin tinggi pendapatan yang diperoleh responden.

Selain luas lahan garapan, jumlah jenis tanaman sudah produksi juga berpengaruh terhadap peningkatan pendapatan responden. Hasil penelitian menunjukan sebagian kecil responden $(33,33 \%)$ yang berpendapatan sangat tinggi hanya memiliki luas lahan 1,5 ha. Data lain yang juga menunjukan peran jumlah jenis tanaman dapat meningkatkan pendapatan responden yaitu diketahui bahwa ada responden yang luas pengusahaan lahannya hanya 0,5 ha, tetapi pendapatanya $1 / 2$ dari responden yang memiliki luas lahan 2 ha.

\section{b. Pendapatan dari kegiatan non agroforestri}

Pendapatan responden dari kegiatan non agroforestri yaitu Rp 1.000.000/KK/TahunRp 35.853.000/KK/Tahun, dengan pendapatan rata-rata sebesar Rp 6.321.690/KK/Tahun. Sebagian besar responden (Gambar 2) mengusahkan kegiatan non agroforestri berladang. Jumlah responden yang melakukan kegiatan non agroforestri berladang sebanyak $8 \mathrm{KK}$ atau $33,33 \%$. Jenis kegiatan non agroforestri responden dapat dilihat pada Tabel 3. 
Tabel 3. Jenis kegaiatan non agroforestri yang diusahakan responden.

\begin{tabular}{llrrr}
\hline No & Jenis Kegiatan non agroforestri & \multicolumn{2}{c}{ Jumlah } & Pendapatan total \\
\cline { 3 - 4 } & & KK & $(\%)$ & Re/KK/Tahun \\
\hline 1 & Berladang & 8 & 33,33 & 191.292 .000 \\
2 & Berdagang & 4 & 16,67 & 9.466 .000 \\
3 & Jasa ojek & 6 & 25,00 & 37.510 .000 \\
4 & Berternak & 2 & 8,33 & 16.284 .000 \\
5 & Buruh tani & 3 & 12,50 & 4.929 .000 \\
6 & Bertani sawah & 1 & 4,17 & 6.030 .000 \\
\hline Jumlah & $\mathbf{2 4}$ & $\mathbf{1 0 0 , 0 0}$ & $\mathbf{2 6 5 . 5 1 1 . 0 0 0}$ \\
\hline Sumber: Data primer (2015). & \multicolumn{3}{c}{}
\end{tabular}

Jenis kegiatan non agroforestri berladang memberikan hasil lebih tinggi dari jenis kegiatan lainnya, rata-rata pendapatan yang dapat diperoleh responden dari kegiatan berladang yaitu sebesar Rp 23.911.500/KK/Tahun. Pendapatan ini dikategorikan tinggi dibandingkan dengan perolehan dari jenis kegiatan non agroforestri lainnya ataupun dalam pengusahan lahan HKm pada luas lahan yang paling sempit, hal ini karena kegiatan berladang dilakukan responden pada lahan milik pribadi, dengan jumlah jenis tanaman lebih banyak dan tanaman berkayu (kehutanan) dapat ditebang untuk diperjual belikan.

Berdasarkan hasil penelitian, responden melakukan kegiatan non agroforestri selain untuk mencukupi kebutuhan juga memanfaatkan waktu luang. Waktu luang responden adalah waktu disela-sela memelihara lahan pada masa pasca panen hingga musim panen berikutnya. Pemeliharaan lahan mengikuti jenis tanaman utama yang diusahakan. Responden mengusahakan kopi sebagai tanaman utama. Kegiatan pemeliharaan kopi antara lain yaitu pemangksaan, pengendalian gulma, pengendalian hama dan penyakit, dan pemupukan. Menurut hasil penelitian curahan waktu untuk pemeliharaan tanaman kopi antara 30-60 hari/ha/tahun. Responden melakukan pemangkasan tunas-tunas baru setiap 3 bulan sekali. Penyiangan dilakukan responden jika keadaan rumput di lahan sudah mulai tumbuh dan dikendalikan dengan herbisida (racun rumput). Pemupukan dilakukan responden menggunakan pupuk urea, NPK dan pupuk kompos dari kulit kopi.

\section{c. Pendapatan total}

Pendapatan total responden yaitu Rp 4.540.000/KK/Tahun-Rp 71.480.000/KK/Tahun, dengan pendapatan rata-rata $\mathrm{Rp} 28.993 .738 / \mathrm{KK} / \mathrm{Tahun}$. Persentase penyebaran pendapatan responden dapat dilihat pada Tabel 4.

Tabel 4. Pendapatan total responden.

\begin{tabular}{lrrr}
\hline \multirow{2}{*}{ Kategori } & \multicolumn{2}{c}{ Jumlah } & Rp/KK/Tahun \\
\cline { 2 - 3 } & KK & $\%$ & 13.000 .000 \\
Paling rendah & 9 & 21,43 & $13.100 .000-23.000 .000$ \\
Rendah & 7 & 16,67 & $23.100 .000-36.000 .000$ \\
Tinggi & 16 & 38,10 & 36.000 .000 \\
Sangat Tinggi & 10 & 23,81 & \\
\hline
\end{tabular}

Sumber: Data primer (2015).

Sebanyak $16 \mathrm{KK}$ atau 38,10\% responden berpendapatan total dalam kategori tinggi. Hasil penelitian menunjukan bahwa responden yang berpendapatan tinggi, memiliki rata-rata lahan seluas 2 ha, tetapi adapula responden yang luas lahan garapannya hanya 0,75 ha. Responden yang berlahan sempit dan berpendapatan tinggi, dikarenakan memiliki jumlah jenis tanaman yang sudah produksi sama banyaknya dengan responden yang berpendapatan 
tinggi pada luas lahan 2 ha. Selain itu, terbantu pula dari jenis kegiatan non agroforestri yang diusahakan sebagai penyedia jasa ojek.

\section{Tingkat Kesejahteraan}

Berdasarkan kriteria miskin Sajogyo 1997 dalam Ayu (2014), tingkat kemiskinan diukur menggunakan konsep pendapatan per kapita yang disetarakan dengan standar harga beras per kilogram di tempat pada waktu penelitian. Rata-rata harga beras yang dikonsumsi rumah tangga responden sebesar Rp 10.000/kg. Kesehjahteraan responden diasumsikan berdasarkan kriteria miskin level 1 sampai 4 yang belum sejahtera. Sedangkan yang berada dalam kategori cukup dan hidup layak dianggap sejahtera.

Hasil perhitungan menunjukan bahwa tingkat kesejahteraan sebagian besar responden berdasarkan pendapatan dari kegiatan agroforestri kopi di lahan HKm berada dalam level belum sejahtera sebanyak $61,90 \%$ sisanya $38,10 \%$, sejahtera. Responden dalam level belum sejahtera rata-rata memiliki jumlah anggota keluarga sebanyak 5 Jiwa/KK, memiliki luas lahan 1 ha dan pendapatan yang diperoleh hanya cukup untuk kebutuhan sehari-hari. Sedangkan berdasarkan tambahan pendapatan dari kegiatan non agroforestri, level belum sejahtera turun menjadi 50,00\% dan level sejahtera naik menjadi 50,00\%. (Gambar 4).

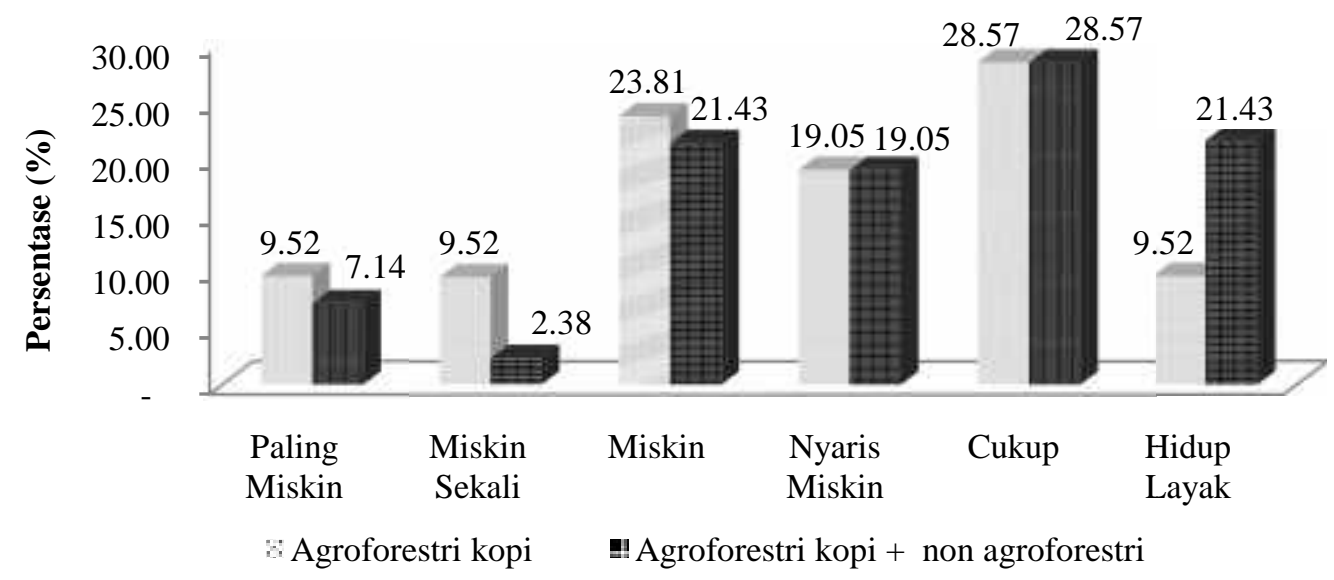

Gambar 4. Distribusi tingkat kesejahteraan anggota Kelompok Karya Tani Mandiri

Kesejahteraan responden meningkat dengan adanya tambahan pendapatan dari kegiatan non agroforestri. Pendapatan dari kegiatan agroforestri kopi yang berjumlah kecil ditambah dengan pendapatan dari kegiatan non agroforestri dapat meningkatkan level tingkat kesejahteraan resonden. Sebagian besar responden yang berada dalam level sejahtera berdasarkan pendapatan total (Agroforestri kopi+non agroforestri) adalah responden yang melakukan kegiatan non agroforestri berladang.

\section{Faktor Produksi Agroforestri Kopi}

Hasil analisis deskriptif menunjukan bahwa luas lahan, jumlah jenis tanaman yang sudah produksi dan jumlah tanggungan keluarga mempengaruhi pendapatan responden. Hubungan antara tingkat pendapatan dengan luas lahan, jumlah jenis tanaman dan jumlah tanggungan keluarga disajikan pada persamaan sebagai berikut:

$\mathrm{Y}=-1.97+6.39 \mathrm{X}_{1}+5.84 \mathrm{X}_{2}-0.130 \mathrm{X}_{3}$

$\mathrm{R}-\mathrm{Sq}(\mathrm{adj})=80.6 \%$

Keterangan

Y :Pendapatan (Jt/KK/Tahun)

$\mathrm{X}_{1} \quad$ :Luas lahan (ha)

$\mathrm{X}_{2} \quad$ :Jenis tanaman (Jenis/ha)

$\mathrm{X}_{3} \quad$ :Jumlah tanggungan keluarga (Jiwa/KK) 
Berdasarkan persamaan, pendapatan responden akan bertambah seiring dengan bertambahnya luas lahan, jenis tanaman yang sudah berproduksi, namun akan berkurang apabila jumlah anggota keluarga bertambah. Penjelasan hasil persamaan pada setiap variabel adalah sebagai berikut:

\section{Luas lahan}

Variabel luas lahan memiliki nilai koefisien 6.39, hal ini menunjukan bahwa penguasaan lahan oleh petani belum mencapai produk marginal dan jika variabel lain tetap luas lahan responden bertambah satu ha, maka pendapatan responden akan meningkat sebesar Rp 6.390.000/KK/Tahun. Sebagian besar responden (79,19\%) memiliki luas kebun 1-2 ha. Besaran pendapatan yang diterima petani berbeda-beda sesuai dengan luasan dan jumlah jenis tanaman yang produktif. Hasil penelitian Patty (2010) menyatakan bahwa luas lahan berpengaruh signifikan terhadap pendapatan petani. Menurut Flamin (2011) penguasaan lahan yang semakin luas sudah jelas akan memberikan keuntungan yang maksimal bagi masyarakat tani hutan. Berdasarkan hal tersebut, pemberian IUPHKm kepada petani perlu ditambah luasannya per KK untuk meningkatkan pendapatan dan kesejahteraan petani.

\section{Jenis tanaman}

Variabel jenis tanaman memiliki nilai koefisien 5.84, hal ini menunjukan jika variabel lain tetap jenis tanaman responden yang produksi meningkat satu jenis, maka pendapatan responden akan meningkat sebesar Rp 5.840.000/KK/Tahun. Rata-rata responden memiliki 3 jenis tanaman yang sudah produksi/ha. Menurut Dida (2002) dalam Olivi (2015) pentingnya penekanan pemilihan jenis berdasarkan pertimbangan teknis dan ekonomis dengan memperhitungkan keuntungan dan kerugiannya karena faktor resiko selalu ada dalam setiap pemilihan jenis pohon tertentu. Tentunya jenis tanaman yang pilih untuk dikembangkan harus sesuai dengan Pratuaran Menteri no P.88/Menhut-II/2014.

\section{Jumlah tanggungan keluarga}

Variabel jumlah tanggungan keluarga memiliki nilai koefisien -0.130 , hal ini menunjukan jika variabel lain tetap jumlah tanggungan keluarga responden bertambah satu jiwa, maka pendapatan responden akan menurun sebesar Rp 1.300.000 KK/Tahun. Sebagian besar responden $(58,38 \%$ ) memiliki jumlah tanggungan keluarga 3-5 jiwa/kk, dalam hal ini jumlah tanggungan keluarga dapat mengurangi pendapatan dan meningkatkan biaya pengeluaran.

\section{KESIMPULAN}

1. Struktur pendapatan petani terdiri dari kegiatan agroforestri kopi di lahan HKm sebesar $\mathrm{Rp}$ 14.649.631/KK/ha/Tahun dan $\mathrm{Rp} 6.321 .690 / \mathrm{KK} /$ Tahun dari kegiatan non agroforestri.

2. Tingkat kesejahteraan petani kategori sejahtera sebanyak $38,10 \%$, sisanya $61,90 \%$ belum sejahtera dari kegiatan agroforestri kopi dan berdasarkan pendapatan total (kegiatan agroforestri kopi + non agroforestri) sebanyak 50,00\% petani sejahtera, sisanya $50,00 \%$ belum sejahtera.

3. Faktor yang mempengaruhi pendapatan petani agroforestri kopi yaitu luas lahan garapan dan jumlah jenis tanaman. 


\section{DAFTAR PUSTAKA}

Ayu, H. Y., R. Qurniati., R. Hilmanto. 2014. Analisis finansial dan komposisi tanaman dalam rangka persiapan pengajuan izin HKm. Jurnal Sylva Lestari. 3(1):34-38.

Cahyono, A. S. 2011. Faktor-faktor yang mempengaruhi petani menyadap pinus di Kawasan Hutan dengan Tujuan Khusus (KHDTK) Gombong. Jurnal Teno Hutan Tanaman. 4(2):51-52.

Kementrian Kehutanan. 2014. Peraturan Menteri Republik Indonesia Nomor P.88/MenhutII/2014 Tentang Hutan Kemasyarakatan. Kemenhut Republik Indonesia. Jakarta.

Dinas Kehutanan Provinsi Lampung. 2014. Rencana Pengelolaan Jangka Panjang KPHL Batutegi tahun 2014-2023. Lampung.

Flamin. A. 2011. Analisis pengaruh hubungan faktor-Faktor sosial ekonomi di Hulu DAS Poleang. Jurnal Agriplus. 21(2):134.

Hakam, A. 2012. Usaha Menciptakan Generasi Muda yang Tangguh. Diakses pada 2 November 2015. https://arifinhakam.wordpress.com.

Lestari, A. D. 2011. Analisis pendapatan masyarakat pengelola hutan kemasyarakatn (HKm) di register 30 Gunung Tanggamus. Skripsi. Jurusan Kehutanan Fakultas Pertanian Universitas Lampung. Lampung. 31-40p.

Olivi, R. 2015. Kontribusi agroforestri terhadap pendapatan petani di Desa Sukoharjo I Kecamatan Sukoharjo Kabupaten Pringsewu. Skripsi. Jurusan Kehutanan Fakultas Pertanian Universitas Lampung. Lampung. 27p.

Patty, Z. 2010. Kontribusi komoditi kopra terhadap pendapatan rumah tangga tani di Kabupaten Halmahera Utara. Jurnal Agroforestri. 3(3):51-57.

Pohan, A. R. 2008. Analisis usahatani dan faktor-faktor yang mempengaruhi pendapatan petani wortel di Desa Gajah, Kecamatan Simpang Empat, Kabupaten Karo. Skripsi. Fakutaltas Petanian Universitas Sumatra Barat. Medan. 38p.

WHO. Kriteria Baru Kelompok Usia. Diakses pada 1 November 2015. http://erabaru.net.

Zega, S. B., P. Agus., T. Martial. 2013. Analisis pengelolaan agroforestry dan kontribusinya terhadap perekonomian masyarakat. Jurnal Peronema Forestry Science. 2(2):152162. 
Vol. 4 No. I, Januari 2016 (I-ID)

Halaman ini sengaja dikosongkan 